\title{
MEETING SUMMARIES
}

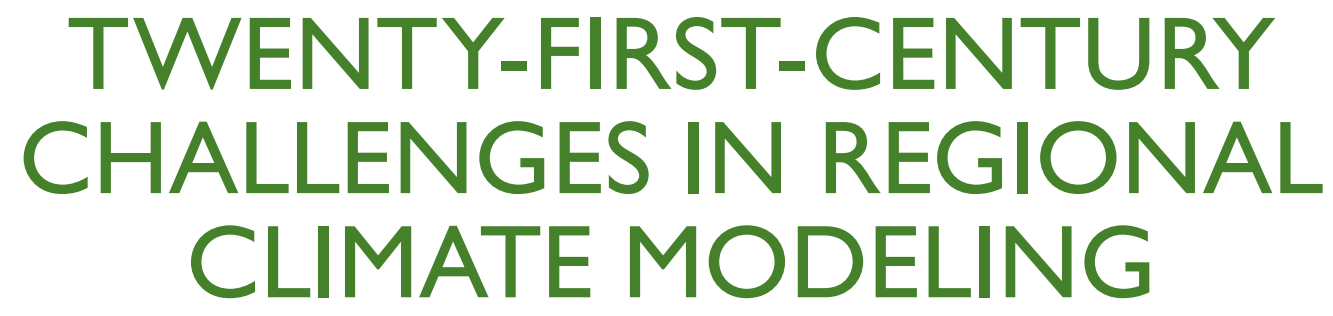

by Markku Rummukainen, Burkhardt Rockel, Lars Bärring, Jens Hesselbjerg Christensen, and Marcus Reckermann

$R$ esearch on regional climate modeling has remarkably expanded during the last few years (Arritt and Rummukainen 2011; Rummukainen 2010; WCRP 2014). This expansion can be seen in the increased number of research groups and world regions of interest to modelers and end users. But perhaps more importantly, the models used by the community are refined with additional complexity and operate on an increasingly finer spatial and vertical resolution. While these changes have given rise to new challenges in model evaluation (e.g., fine-resolution model output requires comparable evaluation data), the expansion of the field implies a greater availability of regional-scale climate

AFFILIATIONS: RUMMUKAINEN-Centre for Environmental and Climate Research, Lund University, Lund, Sweden; RockELInstitute for Coastal Research, Helmholtz-Zentrum Geesthacht, Geesthacht, Germany; BÄrRING—Rossby Centre, Swedish Meteorological and Hydrological Institute, Norrköping, Sweden, and Centre for Environmental and Climate Research, Lund University, Lund, Sweden; CHRISTENSEN-Danish Meteorological Institute, Copenhagen, Denmark; RECKERMANN — International Baltic Earth Secretariat, Helmholtz-Zentrum Geesthacht, Geesthacht, Germany CORRESPONDING AUTHOR: Markku Rummukainen, Centre for Environmental and Climate Research, Lund University, Sölvegatan 37, SE-223 62 Lund, Sweden

E-mail: markku.rummukainen@cec.lu.se

DOI:I0.II75/BAMS-D-|4-002I4.I

In final form 23 January 2015

(C)2015 American Meteorological Society

\section{THIRD INTERNATIONAL LUND REGIONALSCALE CLIMATE MODELLING WORKSHOP}

WHAT: A total of 217 participants from 36 countries discussed scientific advancements in regional climate modeling over the past 5 years as well as presented prospects in the field. More than 200 posters and papers were presented.

WHEN: $16-19$ June 2014

WHERE: Lund, Sweden

information, including climate-change projections for applications.

In the Third International Lund Regional-Scale Climate Modelling Workshop (Bärring et al. 2014), which follows the workshops in 2004 (Bärring and Laprise 2005) and 2009 (Arritt and Rummukainen 2011; Rockel et al. 2009), general and specific developments in regional climate modeling over the last 5 years were reviewed. The workshop focused on pertinent issues and challenges and showcased new developments that further advance the science necessary to meet expectations and demands from the wider scientific community and user groups. The workshop addressed four specific themes. These are briefly presented in the following sections.

\section{REGIONAL CLIMATE SYSTEM MODELS.}

Regional climate models (RCM) typically consist of atmospheric and land surface components. In some regions, additional climate system elements have 
significant influence on local-to-regional conditions and may also give rise to specific feedback under global warming. Coupled modeling at regional scales has made advances with some RCMs evolving to coupled models of atmosphere-ocean-sea ice, climate-vegetation, climate-biogeochemistry, and aerosols. This is a development akin to and in step with global climate models (GCM) being developed into Earth system models that advance Earth system science.

Coupled regional atmosphere-ocean-sea ice models overcome the inner-domain dependency of RCMs from the driving GCM by simulating a physically consistent sea surface temperature (SST). Such RCM development includes the Baltic Sea, the Mediterranean Sea, and the Arctic region. Examples were also presented of coupling hydrology, waves and sea spray, sediments, and vegetation.

It is clear that regional climate is influenced by the large-scale circulation and thus the overall global climate. What remains less explored is whether RCMs can disentangle "upstream" influences from regional and local processes associated with orography, vegetation features, and coastal and similar features when they are resolved on a higher scale than in most GCMs.

VERY HIGH-RESOLUTION RCMS. A few years ago, $25 \mathrm{~km}$ was considered to be high resolution in RCMs, although some models were pushing the envelope using short simulations. Now, more models are being applied at horizontal resolutions of $5-10 \mathrm{~km}$ and some down to $1-2 \mathrm{~km}$. This requires developments in model dynamics and physical parameterizations, including nonhydrostatic models.

Very high (convection permitting) horizontal resolution eliminates the need for convective parameterizations, which has allowed for improved simulations of diurnal cycles of convection and precipitation, including onset, duration, and intensity, as well as of tropical cyclone (TC) intensity and fine structure of the TC eyewall. Better representation of orographic/topographic features can further improve simulations of spatial patterns (e.g., precipitation and winds) associated with small-scale orographic forcing: heavy precipitation, local wind patterns, and urban canopy effects.

Very high-resolution RCM results have provided new insights: for example, (i) soil moistureprecipitation feedback may show opposite signs when convective precipitation is explicitly simulated rather than parameterized, (ii) extreme precipitation may show different changes compared to simulations with parameterized convection and there may be changes in the diurnal timing of rainfall (e.g., increased precipitation only at certain times of the day), and (iii) urban effects (e.g., temperature extremes) are now being resolved.

High resolution, however, is not a panacea. Although convective parameterizations are not needed, other schemes are still needed and can be further improved, such as shallow convection (a smaller-scale process than for general/deep convection), radiative transfer, cloud microphysics, turbulence, and diffusion. Nor is it certain that overall model biases will be reduced at high resolution. For example, mean bias is not always reduced by increasing resolution because many processes are still parameterized.

Whether vertical resolution should be increased alongside horizontal resolution remains to be studied. So far, convection-permitting RCMs commonly use the same vertical resolution as coarser-resolution applications because increasing vertical resolution is not as easy as increasing horizontal resolution. There are indications that increasing vertical resolution is important for simulating surface winds particularly related to nighttime wind structure in the stable nocturnal boundary layer.

Another open issue concerns land surface and whether it is important to incorporate dynamic vegetation at this scale for the simulation of soil/ land surface feedback. Urban effects may likewise be important to cover.

\section{CHALLENGES FOR RCM EVALUATION AND APPLICATION. RCMs with new compo-} nents and higher resolution bring about new model evaluation issues and inform the value-added aspect of downscaling. There are various new developments.

Fundamental limitations of observations for use in RCM evaluation include limited records covered by the time series, lack of information on some parameters and processes, and lack of sufficiently high spatial and temporal (e.g., subdaily) resolution. The spatial and temporal resolution of available observational datasets puts constraints on model evaluation, including high-resolution RCMs. Another pertinent issue is the difference between observational data (station data, but also gridded products) and RCM grid data, and how these are best compared.

RCMs' added value in time-mean quantities and maps is well established in regions of strong local, finescale forcing in the presence of contrasting 
orographic features, coastal areas, etc. (Flato et al. 2014). Time-averaging blanks out a lot of the added value. Spatial spectra of variables on the scale of RCMs can have two orders of magnitude more variance in the transient than in the stationary time average. Also, things shift toward higher frequency. This has been demonstrated for precipitation in many studies. Studies should more systematically focus on high-order moment statistics, distributional aspects of probability density functions, extreme value analysis, and multivariate analysis to address high temporal frequency variability such as subdaily variations (e.g., diurnal cycle) and phenomena such as low-level jets, monsoons, convection, and orography-induced wind regimes. Added value may furthermore be highly dependent on the particular spatial scales that we look at; it may manifest more clearly in recent very high-resolution simulations with grid resolutions of $1-10 \mathrm{~km}$, rather than at the $25-50-\mathrm{km}$ resolution employed for the last two decades.

There may also be a fundamental difference between looking for added value in the simulation of the current climate versus the simulated climate-change signal. The processes responsible for both types of added value are very different. A specific feature that is better captured at high resolution than coarser resolution, but not subject to additional change compared to what occurs on the larger scale, can constitute added value in current climate but not necessarily in climate-change projection. The opposite may be the case for some nonlinear behavior. Additional values of finerresolved climate-change simulations (than those of GCMs) can also be demonstrated by highlighting the need for other fields to "catch up" when representing processes at finer resolutions. For example, a finer-resolved atmosphere could better enable a finer-resolved ocean model.

As RCM results are used in climate impact research, the question of added value also needs to be asked in terms of "who" will gain added value; that is, the issue needs to be approached from the users' perspective, not only in terms of scientific model analysis. Users in the impact domain, for example, may be interested in the climate-change signal at a particular point location and may experience scaled GCM data equally sufficient as RCM data. The benefits of RCM data are more obvious for impact models/tools making use of observed data in a gridded format or when several input variables are required and in regions with variable geography and other relevant features.
RCM ENSEMBLES. Coordinated experimentation with RCMs has advanced. The major development has been the international Coordinated Regional Climate Downscaling Experiment (CORDEX). Nevertheless, there are open-ended issues such as the best design for a regional climate model ensemble, the choice of GCMs and RCMs, possible weighting of ensemble members, model independence, and whether ensemble variance provides a good estimate of projection uncertainty. Some of these issues are generic and apply to both GCMs and RCMs. The multitude of new GCM runs in phase 5 of the Coupled Model Intercomparison Project (CMIP5) can enable better ensemble strategies for RCMs compared to ensembles of opportunity. The CMIP6 efforts have, among other goals, the potential to further enable RCM studies by including this perspective already when designing coordinated simulation experiments.

One open issue is whether RCMs should in larger numbers follow the GCM community into the seasonal and even decadal prediction domain. This may be more relevant in some places than othersthis is, in regions where there is predictability of largescale systems, such as El Niño-Southern Oscillation (ENSO), which has a large impact on regional weather (e.g., Australia). This could be an opportunity for the RCM community, as the quality of the boundary conditions should be fairly good relative to climatechange projections.

Many users of RCM output are within the impact and adaptation community. These practitioners may not always be familiar with the opportunities and limitations of RCM data or aware of how best to use the data for risk assessment and planning activities. Utility of ensemble data and ensemble-based probability information to this community is a key issue. The average or median value is just one piece of information from an ensemble.

OUTLOOK. The RCM community is more organized today than just a few years ago. However, as each specific study has a specific reason for using RCMs, be it pure scientific interest (such as understanding a key regional climate system phenomenon) or generation of utility for regional impact assessments, available studies are not easily compared and shared for comprehensive community analysis. Further coordinated activities should also be developed-for example, on high-resolution RCM studies and further refined investigation of added value.

Further steps should be taken to involve the users benefiting from RCM studies. For example, in the 
United States there is a big push for biofuels, which potentially means replacing pasture lands and crops by plants for biomass. It changes roughness, evapotranspiration, and so forth, thus affecting the local climate. In addition to improving the physics, experiments may also be designed with knowledge needs in mind, such as policy and practitioners' decisions.

There are also, still, time lags between the complementary efforts within the global GCM and RCM communities. RCMs need boundary conditions from GCMs and thus developments in the latter field can only become available to the former later. At the same time, RCMs can explore high-resolution and specific phenomena in more detail than GCMs and highlight model development as well as evaluation avenues for the global models.

ACKNOWLEDGMENTS. The workshop was jointly organized and funded by Lund University, the Swedish Meteorological and Hydrological Institute (SMHI), the Danish Meteorological Institute (DMI), HelmholtzZentrum Geesthacht (HZG), and the International Baltic Earth Secretariat. A scientific committee was responsible for preparing the workshop content and the scientific program, as well as for peer reviewing the contributions.

We are grateful for a generous endorsement and financial support from the following organizations: the World Meteorological Organization (WMO), the World Climate Research Programme (WCRP), the Swedish Research Council and the Swedish Research Council Formas, the Centre for Regional Change in the Earth System (CRES), the SMHI Rossby Centre, the Mistra-SWECIA research programme, the strategic research areas MERGE and eSSENCE, and the programme for Risk Information on Climate Change (SOUSEI).

\section{REFERENCES}

Arritt, R. W., and M. Rummukainen, 2011: Challenges in regional-scale climate modeling. Bull. Amer. Meteor. Soc., 92, 365-368, doi:10.1175/2010BAMS2971.1.

Bärring, L., and R. Laprise, Eds., 2005: Extended Abstracts, High-Resolution Climate Modelling: Assessment, Added Value and Applications. Lund, Sweden, WMO/WCRP, Lund University, Lund Electronic Reports in Physical Geography 5, 133 pp.

—, M. Reckermann, B. Rockel, and M. Rummukainen, Eds., 2014: Proc. Third Int. Lund Regional-Scale Climate Modelling Workshop: 21st Century Challenges in Regional Climate Modelling. Lund, Sweden, Lund University, International Baltic Earth Secretariat Publ. 3, 387 pp. [Available online at www.baltic-earth .eu/events/RCM2014/Material/IBESPS_No.3_low.pdf.]

Flato, G., and Coauthors, 2014: Evaluation of climate models. Climate Change 2013: The Physical Science Basis, T. F. Stocker et al., Eds., Cambridge University Press, 741-866.

Rockel, B., L. Bärring, and M. Reckermann, Eds., 2009: Proc. Second Int. Lund RCM Workshop: 21st Century Challenges in Regional-Scale Climate Modelling. Lund, Sweden, Lund University, International BALTEX Secretariat Publ. 41, 292 pp. [Available online at www.baltex-research.eu/RCM2009/Material /RCM2009_Proceedings_low.pdf.]

Rummukainen, M., 2010: State-of-the-art with regional climate models. Wiley Interdiscip. Rev.: Climate Change, 1, 82-96, doi:10.1002/wcc.8.

WCRP, 2014: Report of the International Conference on Regional Climate-ICRC 2013. WCRP Rep. 2/2014, 25 pp. [Available online at http://cordex2013 .wcrp-climate.org/cordex 2013 _documents /ICRC2013_report.pdf.] 